\title{
The occult aftermath of boxing
}

\author{
Gareth W Roberts, David Allsop, Clive Bruton
}

Department of

Anatomy and Cell

Biology, St Mary's

Medical School,

London

GW Roberts

Department of

Molecular Biology,

Psychiatric Research

Institute of Tokyo,

Japan

D Allsop

Division of Psychiatry, Clinical Research

Centre, Harrow

Department of

Neuropathology,

Runwell Hospital,

Wickford, Essex

C Bruton

Correspondence to:

GW Roberts, Department of

Anatomy and Cell Biology,

St Mary's Medical School,

Kingdom.

Received 22 May 1989 and in

revised form 12 September

1989.

Accepted 2 November 1989

\begin{abstract}
The repeated head trauma experienced by boxers can lead to the development of dementia pugilistica (DP)-punch drunk syndrome. The neuropathology of DP in a classic report by Corsellis et al describes the presence of numerous neurofibrillary tangles in the absence of plaques, in contrast to the profusion of tangles and plaques seen in Alzheimer's disease (AD). The DP cases used in that report were re-investigated with immunocytochemical methods and an antibody raised to the $\beta$-protein present in AD plaques. We found that all DP cases with substantial tangle formation showed evidence of extensive $\beta$-protein immunoreactive deposits (plaques). These diffuse "plaques" were not visible with Congo-red or standard silver stains. The degree of $\beta$-protein deposition was comparable to that seen in AD. Our data indicate that the present neuropathological description of DP (tangles but no plaques) should be altered to acknowledge the presence of substantial $\beta$ protein deposition (plaques). The molecular markers present in the plaques and tangles of DP are the same as those in AD. Similarities in clinical symptoms, distribution of pathology and neurochemical deficits also exist. Epidemiological studies have shown that head injury is a risk factor in AD. It is probable that DP and AD share common pathogenic mechanisms leading to tangle and plaque formation.
\end{abstract}

The trauma to the head experienced by boxers practising their profession is thought to cause dementia pugilistica (DP) or "punch drunk" syndrome. ${ }^{1}$ Several classic studies have established that DP presents as a relatively stereotyped clinical picture characterised by neurological evidence of damage to pyramidal, extrapyramidal and cerebellar systems with associated psychosis, memory loss or dementia, personality change and social instability. ${ }^{23}$ Symptoms can be progressive and may develop late in a boxer's career or even years after retirement from the ring. Available evidence suggests that the severity of the syndrome correlates with the length of the boxers career and total number of bouts, and has an overall incidence of about $17 \%$ in professional boxers which rises with age $^{3}$ (although this may be an underestimate; see discussion in ${ }^{4}$ ).

Three stages of clinical deterioration are recognised and, although progression of symptoms occurs, the syndrome can remain clinically stable at any level. The first stage consists of affective disturbances and psychotic symptoms. During the second stage an accentuation of social instability and psychiatric symptoms occurs along with memory loss and the signs/symptoms of Parkinsonism develop. The final stage consists of a decrease in general cognitive functioning-progressing to dementia together with pyramidal tract disease. Several years elapse between stages.

The neuropathology of the condition, described in a classic study, ${ }^{5}$ consists of abnormalities of the septum pellucidum, focal scarring of the cerebellum and loss of pigmented neurons in the substantia nigra. A striking finding was the presence of numerous neurofibrillary tangles in the cortex (particularly in the temporal lobe) in the absence of appreciable numbers of plaques. A marked contrast to the situation typically seen in Alzheimer's disease (AD). While most of the damage present in DP brains is accountable in terms of trauma suffered during the linear and rotational acceleration caused by blows to the head, ${ }^{5}$ the extensive neurofibrillary change in the absence of plaque formation is a puzzling phenomenon. The tangles of DP are structurally and immunologically ${ }^{6}$ indistinguishable from the tangles which are thought to be central to the disease process in $\mathrm{AD}$. On this basis it has been suggested that studies of DP may provide aetiological insight for $\mathrm{AD} . .^{56}$ However, this suggestion has been dismissed on the basis that plaques are the central component of $\mathrm{AD}$ and as cases of DP show no appreciable plaque formation then the processes involved must be radically different.

The protein component of plaque and cerebrovascular amyloid in $\mathrm{AD}$ ( $\beta$-protein) was recently isolated and sequenced ${ }^{78}$ and cDNA clones encoding this protein as part of a larger precursor were identified. ${ }^{9}$ The corresponding amyloid precursor gene was mapped to chromosome 21 , and this gene seems to be expressed in a wide variety of tissues with particularly high levels of expression in the brain. ${ }^{9}$ Whether or not the paired helical filaments also contain $\beta$-protein is doubtful and is still a matter of considerable dispute. ${ }^{10}$ Monoclonal antibodies produced by one of us to a synthetic peptide, corresponding to a subsequence of $\beta$-protein could specifically label plaque and cerebrovascular amyloid in $\mathrm{AD}$, Down's syndrome and brains in the elderly. ${ }^{11}$

Recently a formic acid pretreatment method 
was developed for the enhancement of amyloid immunoreactivity. ${ }^{12}$ This technique has been used to examine the morphology and distribution of $\beta$-amyloid immunoreactive deposits in neurodegenerative diseases. ${ }^{1314}$ This enhancement method has been shown reveal diffuse plaque-like lesions that are difficult or impossible to detect with conventional Congo red or silver stains ${ }^{1314}$. During our studies, sections from some cases of DP were processed in a similar fashion by one of us (GWR) out of curiosity. The initial results caused a review of our archival material. We now report on the results of our "serendipitous" investigations.

\section{Subjects and methods}

Archival formalin-fixed material from the temporal lobe was examined from 14 of the 15 cases of DP originally reported by Corsellis $e t$ $a l,{ }^{5}$ one additional case of a boxer who died during a fight, three additional cases 'of professional boxers and two amateur boxers (table 1): each case had previously been investigated to establish career details and had undergone extensive neuropathological examination. The extent of tangle and plaque formation was established by silver and Congo red staining (table 1). Paraffin embedded 20 $\mu \mathrm{m}$ sections were stained by haemotoxylin eosin and Congo red and by immunocytochemical methods (PAP) using a well characterised monoclonal antibody $4 \mathrm{D} 12 / 2 / 6$ raised to a synthetic peptide corresponding to residues $8-17$ of the $\beta$-protein amyloid. ${ }^{11}$ Immunostaining was carried out with or without a fifteen minute pre-incubation on $70 \%$ formic acid (a step which has been shown to enhance the immunoreactivity of various systemic and cerebral amyloids). ${ }^{12}$ Sections were incubated with the primary antibody (dilution 1:1000 ascites fluid for one hour) and then with a second layer anti-mouse IgG peroxidase conjugated antisera (Miles-Yeda 1:100 for 30 minutes). The reaction site was visualised by a final incubation in a $0.05 \%$ diaminobenzidene solution.

For comparison, sections from 20 confirmed cases of Alzheimer's disease and 20 age-matched controls were investigated in a similar fashion.

\section{Results}

No formic acid pre-treatment. Amyloid plaque deposits in $\mathrm{AD}$ and (to a much lesser extent) older controls stained positively with the anti $\beta$-protein antibody. The number, distribution and appearance of the immunoreactive plaques was essentially identical to that observed with the Congo red stain suggesting that the two procedures detect the same population of plaques, although there is evidence that immunostaining is a more sensitive technique. ${ }^{1013}$ Examination of the DP cases showed that most had little or no Congo red staining and levels of $\beta$-protein immunoreactivity were indistinguishable from that seen in controls of a similar age. A few cases showed moderate levels of $\beta$-amyloid plaque staining as expected given that these cases had been previously shown to have some plaques present by silver and Congo red staining methods. There was little evidence of amyloid angiopathy.

Formic acid pre-treatment. All cases of $\mathrm{AD}$ showed increased levels of immunostaining after formic acid pre-treatment. In many instances numerous additional small areas of diffuse immunostaining that were not visible in sections stained by conventional histo-

Table 1 Biographical and neuropathological details of cases

\begin{tabular}{|c|c|c|c|c|c|c|}
\hline \multirow[b]{2}{*}{ Case } & \multirow[b]{2}{*}{ Age } & \multicolumn{2}{|l|}{ Details of cases } & \multicolumn{3}{|l|}{ Neuropathology ${ }^{1}$} \\
\hline & & Boxing career (years) & No fights & Cavum septum & Tangles & Plaques \\
\hline $\begin{array}{l}\text { Professiona } \\
1 \\
2 \\
3(5)^{\star} \\
4 \\
5(7) \\
6(3) \\
7(1) \\
8 \\
9(11) \\
10(10) \\
11(4) \\
12(8) \\
13(9) \\
14(2) \\
15(6)\end{array}$ & $\begin{array}{l}22 \\
53 \\
60 \\
61 \\
62 \\
63 \\
63 \\
65 \\
67 \\
67 \\
69 \\
71 \\
72 \\
77 \\
83\end{array}$ & $\begin{array}{l}3 \\
25 \\
18 \\
15 \\
20 \\
13 \\
14 \\
20 \\
20 \\
15 \\
25 \\
23 \\
10 \\
17 \\
25\end{array}$ & $\begin{array}{c}3 \text { (died during fight) } \\
>100 \\
>100 \\
150 \\
400 \\
300 \\
400 \\
>200 \\
? \\
? \\
600 \\
565 \\
? \\
700 \\
500\end{array}$ & $\begin{array}{l}+ \\
+ \\
+ \\
+ \\
+ \\
+ \\
+ \\
+ \\
+ \\
+ \\
+ \\
+ \\
+ \\
+ \\
+\end{array}$ & $\begin{array}{l}+ \\
+ \\
++ \\
+++ \\
+++ \\
+++ \\
+++ \\
+ \\
+ \\
++ \\
++ \\
++ \\
++ \\
++ \\
++\end{array}$ & $\begin{array}{l}\bar{z} \\
\bar{z} \\
\bar{z} \\
\bar{z} \\
\frac{ \pm}{ \pm} \\
\frac{ \pm}{ \pm} \\
++\end{array}$ \\
\hline $\begin{array}{l}\text { Amateur } \\
16(13) \\
17(15) \\
18(14) \\
19 \\
20^{\mathrm{A}}\end{array}$ & $\begin{array}{l}57 \\
58 \\
61 \\
68 \\
72\end{array}$ & $\begin{array}{r}15 \\
5 \\
20 \\
2 \\
2\end{array}$ & $\begin{array}{l}>100 \\
>\quad 50 \\
>100 \\
<10 \\
<10\end{array}$ & $\begin{array}{l}+ \\
\pm \\
\pm \\
\pm \\
-\end{array}$ & $\begin{array}{l}\frac{++}{+} \\
\frac{+}{+}+\end{array}$ & $\frac{+t+}{\frac{+}{+}}$ \\
\hline $\begin{array}{l}\mathrm{AD} \text { cases } \\
\mathrm{N}=20\end{array}$ & $55-85$ & $\mathbf{N} / \mathbf{A}$ & N/A & 一 & $++(\mathrm{MIN})$ & $++(\mathrm{MIN})$ \\
\hline $\begin{array}{l}\text { Controls } \\
\mathrm{N}=20\end{array}$ & $58-90$ & $\mathbf{N} / \mathbf{A}$ & N/A & - & $+(\mathrm{MAX})$ & $++(\mathbf{M A X})$ \\
\hline
\end{tabular}

Tangle and plaque assessed by routine silver stains.

* Case No. in Corsellis et al.

A Probable Alzheimer's disease. 
Figure 1 Section of temporal cortex from case 3. $(A)$ Congo red stain and immunostaining using antibody to $\beta$-protein reveals little or no plaque formation. (B) A serial section following formic acid pretreatment and immunostaining with $\beta$ protein antibody. Masses of diffuse $\beta$-protein immunoreactive deposits are visible scattered through all cortical layers $(\times 160)$.

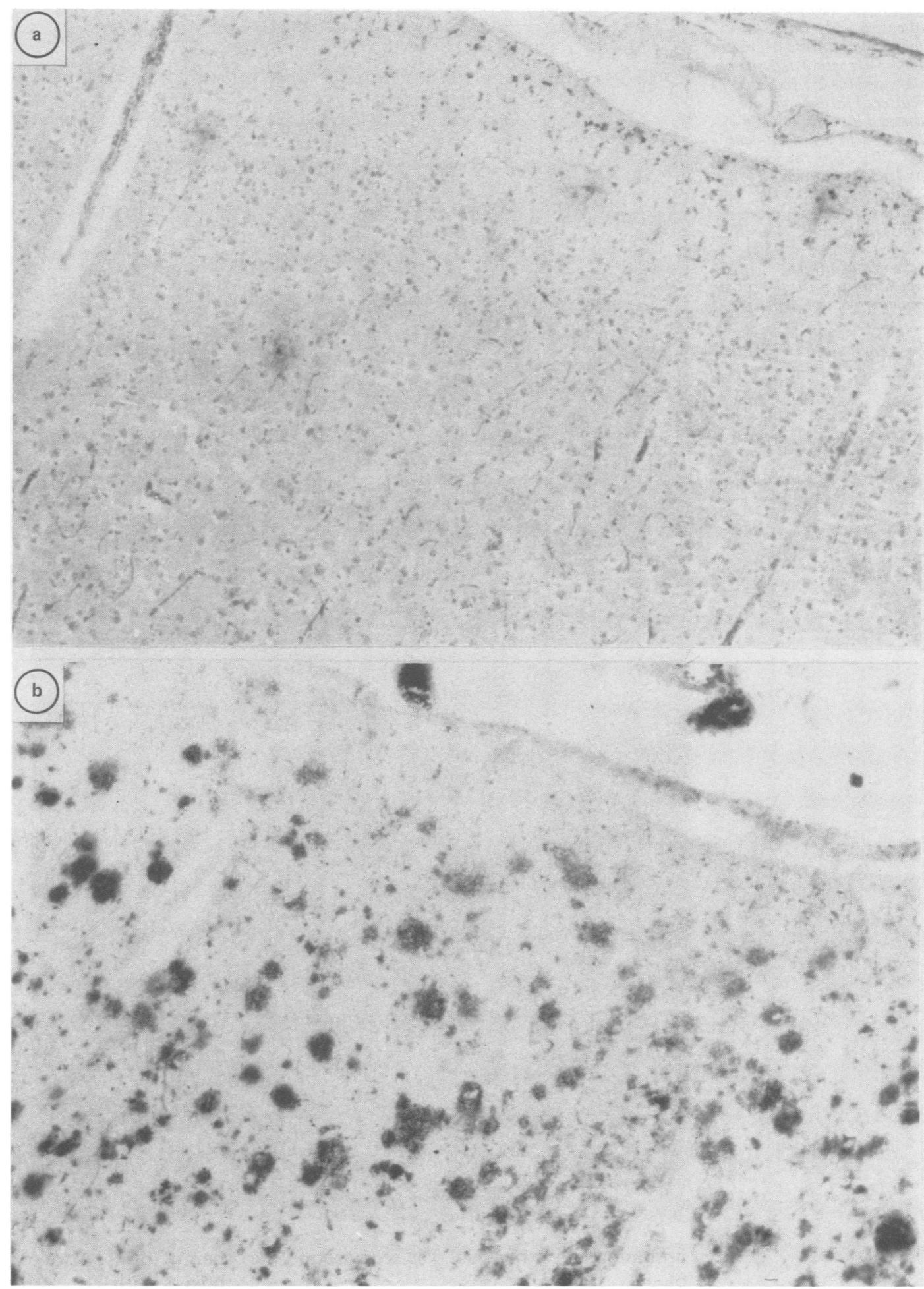

logical methods were observed. However, the older controls showed only an intensification of the limited staining found without pretreatment, with little or no additional immunoreactive lesions being revealed. Such staining in controls was well within the limits seen to occur with increasing age.

Examination of the sections from the brains of boxers was in dramatic contrast, the exception being case 1 who was 22 years old and had had three professional fights. Formic acid pretreatment revealed substantial numbers of hitherto invisible diffuse $\beta$-protein immunoreactive plaques (figs 1,2 and 3 ). These diffuse types of plaque showed no association with abnormal neurites (no "neuritic halo") and ranged in size from $10-200 \mu \mathrm{m}$ in diameter. All cases previously found to contain substantial numbers of tangles but no plaques by silver or Congo red staining showed extensive amounts of $\beta$-protein immunoreactivity, in most cases as extensive as that seen in $\mathrm{AD}$, although the latter cases also contained typical mature Congophilic and argyrophilic plaques in addition to the more diffuse kind of plaque.

There was no marked association between blood vessels and the $\beta$-immunoreactivity of diffuse plaques although a degree of $\beta$-protein 
Figure 2 Temporal cortex of case 6. (A) Large numbers of diffuse $\beta$-protein immunoreactive deposits of varying size are revealed scattered throughout the cortical layers following formic acid pre-treatment $(\times 20)$. Note the scattering of deposits through all cortical layers and the absence of deposits in the white matter (WM). (B) Higher power $(\times 350)$ reveals the diffuse appearance of the $\beta$-protein immunoreactive deposits.
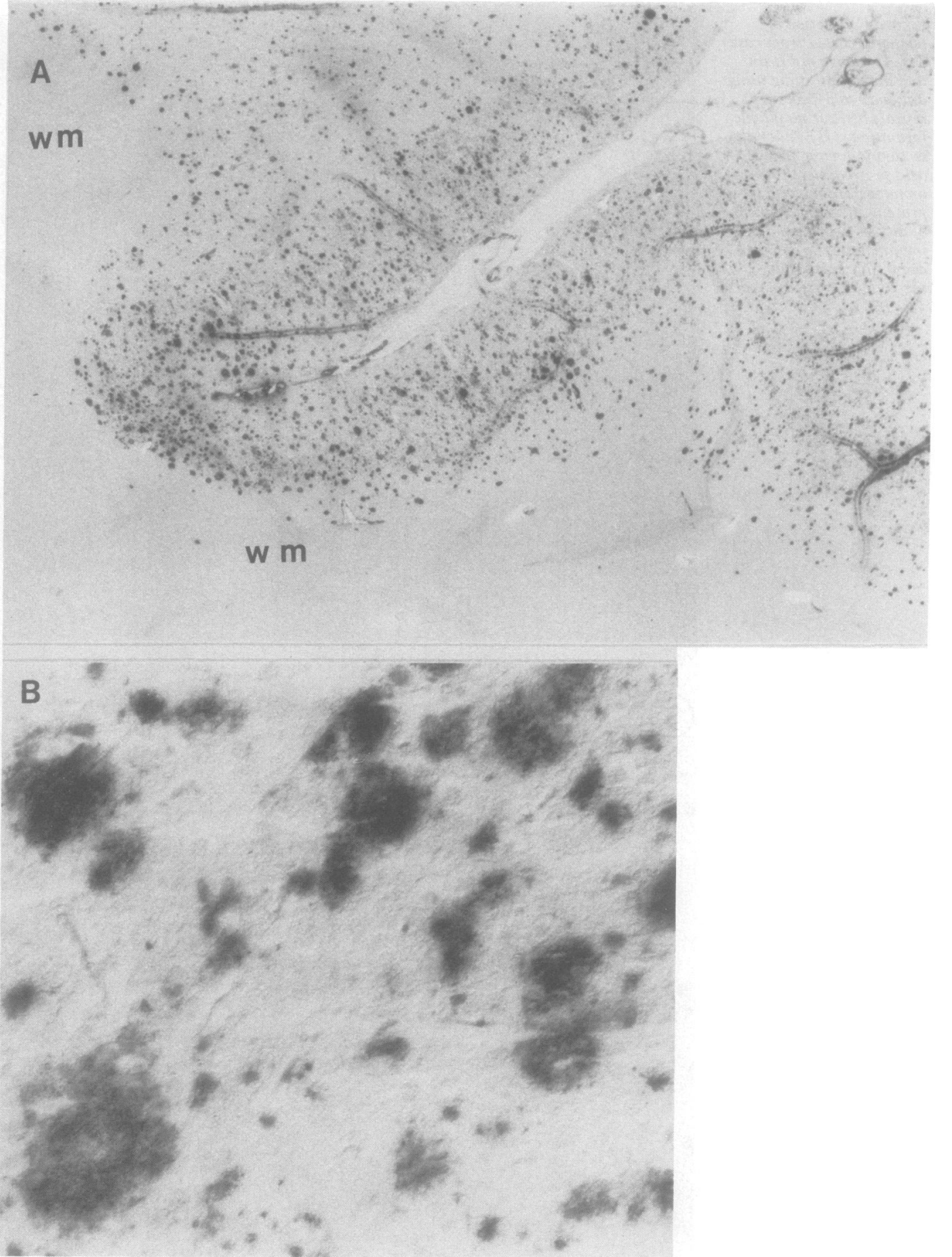

immunoreactive material was seen around the blood vessels.

\section{Discussion}

Although our cases may be regarded as being representative of a past era, recent CT studies reveal evidence of damage in the brains of modern boxers. ${ }^{15}$ It is clear that the physical forces acting on boxers brains remains unchanged and that our findings are still relevant to today's boxers and those of the future. The standard descriptions of the neuropathology of DP note the presence of large numbers of neurofibrillary tangles in the cortex, which is similar to Alzheimer's disease, and emphasise the relative absence of senile plaques (in contrast to $\mathrm{AD}) .^{5}$ Our data show that large num- 
Figure 3 Comparison of typical $\beta$-protein immunoreactive plaque found in Alzheimer's disease. (A) Showing the core and halo of staining with the $(B)$ more diffuse and irregularly shaped $\beta$ protein deposits present in dementia pugilistica cases $(A \times 650 ; B \times 500)$.

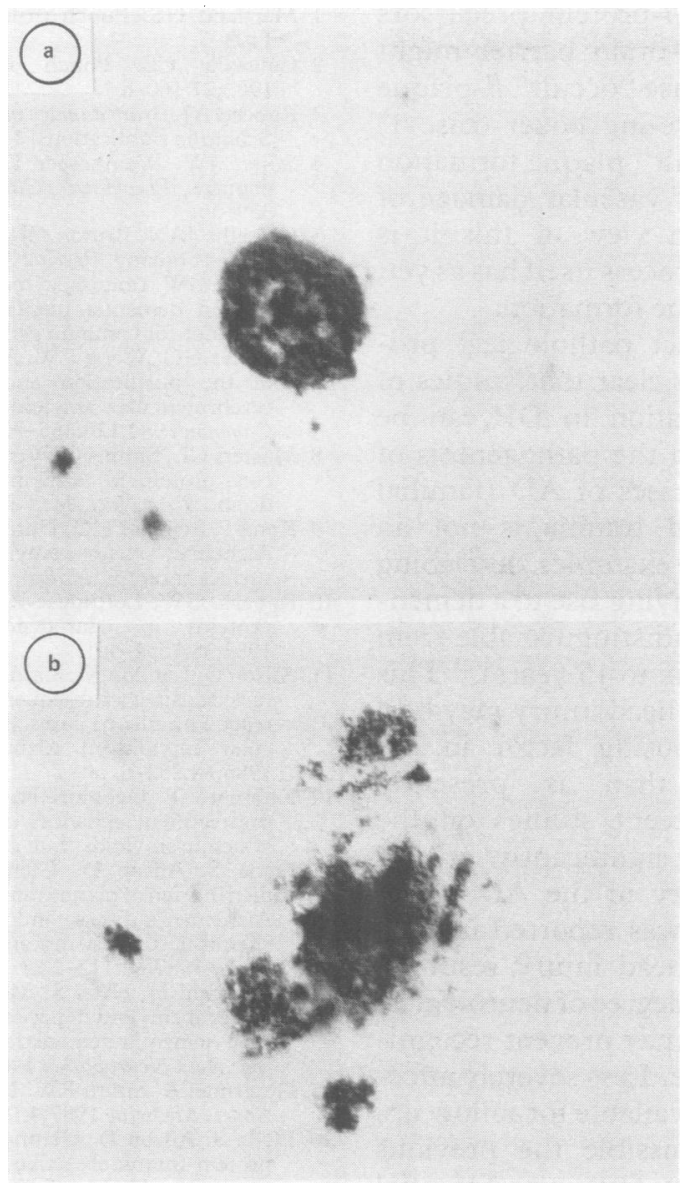

anatomy, neurochemistry, symptomatology, now include the finding of $\beta$-protein immunoreactivity in plaque-like structures in DP. The tangles of DP have identical morphological features and immunoreactivity profiles to those in $\mathrm{AD}^{6}$ The neurofibrillary degeneration in DP is concentrated in the temporal lobe ${ }^{5}$ (the region particularly affected in $\mathrm{AD}$ ) and the set of neurons preferentially affected in DP (the pre $\alpha$-layer of Braak) is also particularly affected in $\mathrm{AD} .^{6}$ Tentative studies suggest that DP cases show atrophy of the basal nucleus of Meynert and cortical cholinergic deficits ${ }^{17}$ and it is well documented that the clinical symptoms of DP (insidious onset, behavioural dis-

Table 2 Detection of amyloid plaques

\begin{tabular}{|c|c|c|c|}
\hline \multirow[b]{2}{*}{ Case } & \multicolumn{3}{|c|}{$\beta$-Amyloid immunostaining } \\
\hline & No Formic Acid & Formic Acid & Silver staining ${ }^{1}$ \\
\hline 1 & - & - & - \\
\hline 2 & - & ++ & - \\
\hline 3 & - & ++ & - \\
\hline 4 & \pm & +++ & - \\
\hline 5 & 二 & ++ & 一 \\
\hline 6 & \pm & +++ & - \\
\hline 7 & \pm & +++ & - \\
\hline 8 & $\bar{t}$ & ++ & - \\
\hline 9 & + & ++ & \pm \\
\hline 10 & + & $+t+$ & \pm \\
\hline 11 & - & ++ & 二 \\
\hline 12 & + & +++ & \pm \\
\hline 13 & \pm & ++ & - \\
\hline 14 & - & +++ & - \\
\hline 15 & ++ & +++ & ++ \\
\hline 16 & ++ & $++t$ & +++ \\
\hline 18 & $\stackrel{ \pm}{+}$ & $\begin{array}{l}++ \\
+\end{array}$ & $\overline{+}$ \\
\hline 19 & + & + & - \\
\hline & ++ & +++ & +++ \\
\hline AD Cases & $+++(\mathrm{MIN})$ & $++($ MIN $)$ & $++(\mathbf{M I N})$ \\
\hline Controls & $++(\mathbf{M A X})$ & $++(\mathbf{M A X})$ & $++(\mathbf{M A X})$ \\
\hline
\end{tabular}

' von Braunmuhls or Bielschowsky (from table 1 ). turbances, progressive dementia) are congruent with those of $\mathrm{AD} .^{15}$ The major pathological differences between $\mathrm{AD}$ and $\mathrm{DP}$ are the additional damage (cavum septum, cerebellar scarring, substantia nigra degeneration) and lack of typical senile plaque formation in DP. ${ }^{5}$ The additional damage can be explained by the severity of punishment to the head received by boxers practising their profession. Most of these additional pathologies can be found to varying degrees in cases of $\mathrm{AD}^{51519}$ from the rare cavum septum to the fairly common degeneration of the substantia nigra. The process of tangle and plaque formation in both conditions may give rise to the dementing syndrome, and it is probable that the pathological mechanisms involved in the formation of these lesions follow a common pathway to some extent, although the initial stimulus for their formation may be different (traumatic in DP versus genetic, infectious aetiology, environmental or traumatic in AD). Here the concept of "Alzheimer's syndrome"-a common response of the brain (plaques and tangles) to a variety of pathological insults-may be useful.

The most interesting question concerns the occurrence of neurofibrillary degeneration in DP in the absence of appreciable numbers of Congophilic and neuritic $\left(\mathrm{T}^{10}\right)$ plaques, but in the presence of diffuse $\beta$-protein immunoreactive lesions. This might be explained by the comparatively young age of the individual when damage occurs (typically 20 's and 30 's), a situation which seems to favour the formation of neurofibrillary tangles. In Guam Parkinson dementia, cases with onset in the fourth decade show tangles with few or absent plaques but the more recent descriptions of Guamanian dementia indicate increased age of onset and a consequent increase in the number of plaques. ${ }^{18}$ Early (presenile) cases of AD can show a profusion of neurofibrillary tangles often with few plaques. ${ }^{19}$ Thus the precise pathological picture seen in "Alzheimer's syndrome" seems to vary depending on the age of the individual. The damage in DP may be due to mechanical shearing forces on long axons/ dendrites. ${ }^{20}$ Cells with long projections or extensive dendritic trees (for example, the projection neurons which contribute to the perforant path and substantia nigra, and basal nucleus of Meynert, neurons which project to the cortex) would be particularly vulnerable to this type of damage. The loss of dendrites due to shearing may explain the paucity of neuritic involvement in the plaques. Such a phenomenon could become even more marked with age since neurons devoid of dendrites would be unable to display the age related dendritic sprouting that occurs in normal and $A D$ brains. ${ }^{21-23}$ This type of mechanism would seem to be more consistent with a neuronal origin of $\beta$-protein amyloid than a serum origin. Alternatively, the possibility of damage to cerebral blood vessels, with the leakage of serum components into the brain, must be considered. The cases used in this study show evidence of significant vascular damage. ${ }^{24}$ The damage to blood vessels is probably directly due to head 
trauma and leakage of $\beta$-protein precursors across a defective blood-brain barrier might conveniently explain diffuse "occult" $\beta$-plaque formation in DP. The young boxer (case 1) showed no signs of "occult" plaque formation despite clear evidence of vascular damage of some years standing. In view of this it is possible that the ageing process itself has as yet, an undefined role in plaque formation.

Regardless of the exact pathological processes involved, it is now clear that studies of plaque and tangle formation in DP can be expected to shed light on the pathogenesis of $\mathrm{AD}$. Although in most cases of $\mathrm{AD}$ (familial cases for example) head trauma is not an obvious factor, there are examples describing instances of head injury giving rise to a dementia neuropathologically indistinguishable from $\mathrm{AD}$ over a long period (six to 15 years). ${ }^{25}$ This raises the possibility that head injury may be a more important predisposing factor in the pathogenesis of $\mathrm{AD}$ than is presently appreciated. In three recent studies on the epidemiology of AD, a significantly greater occurrence of head injury in the $A D$ group compared with controls was reported in each one. ${ }^{26-28}$ Many cases of head injury result in severe disability, and the degree of neurological impairment in survivors may prevent recognition of intellectual decline. Less severely affected persons are often unavailable for follow up. Even if follow up is possible the previous history of head injury may favour preferential documentation of the mechanical and vascular lesions related to trauma rather than the development of Alzheimer-type neuropathology. In large studies of brain damaged patients an insiduous dementia occurring some year after the initial trauma was noted in $11 \%$ and $25 \%{ }^{30}$ of cases, a rate more than double that of the "normal" ageing population. Animal experiments have also shown that head injury has acute and potentially chronic effects on the cholinergic system ${ }^{31}$ and the cholinergic system is primarily the focus of pharmacological research in Alzheimer's disease.

Data from pathological, neurochemical and epidemiological studies together with our immunological data indicate that head injury causing neuronal shearing and/or damage to the vascular system may precipitate the pathological processes which give rise to AD. Given the lack of disease models, further study of animal models of chronic brain damage and subjects with long-term brain damage may provide insights into the pathogenesis of, or mechanisms which generate Alzheimer's disease.

We thank Professor JAN Corsellis for useful discussions and his generosity in encouraging further studies on this material.
1 Martland HS. Punch drunk J Am Med Assoc 1928;91: 1103-7.

2 Courville CB. Punch drunk. Bull LA Neurol So 1962;27:160-8.

3 Roberts AJ. Brain damage in boxers London: Pitman Medical Scientific Publications, 1969.

4 Stiller JW, Weinberger DR. Boxing and chronic brain damage. Psychiatric Clinics of North America 1985;8 339-56.

5 Corsellis JAN, Bruton CJ, Freeman-Brown D. The aftermath of boxing. Psychol Med 1973;3:270-303.

6 Roberts GW. Immunocytochemistry of neurofibrillary tangles in dementia pugilistica and Alzheimer's disease gles in dementia pugilistica and Alzheimer's disease:
evidence for common genesis. Lancet 1988;ii:1456-8.

7 Glenner GG, Wong CW. Alzheimer's disease initial report of the purification and characterisation of a novel of the purification and characterisation of a novel
cerebrovascular amyloid protein. Biochem Biophys Res cerebrovascular amyloid prot
Common 1984;120:885-90.

8 Masters CL, Simms G, Weinmon NA, et al. Amyloid plaque core protein in Alzheimer's disease and Down's syndrome. Proc Natl Acad Sci 1985;82:4245-9.

9 Kang I, Lemaire HG, Unterbeck A, et al. The precursor of Alzheimer's disease amyloid A4 protein resembles a cellsurface receptor. Nature 1987;325:733-6.

10 Roberts GW, Lofthouse R, Allsop D, et al. CNS amyloid proteins in neurodegenerative diseases. Neurology 1988;38:1534-40.

11 Allsop D, Landon M, Kidd M, et al. Monoclonal antibodies raised against a subsequence of senile plaque core proteins raised against a subsequence of senile plaque core proteins react with plaque cores, plaque periphery and cerebovas-
cular amyloid in Alzheimer's disease. Neurosci Lett cular amyloid

12 Kitamoto $\mathrm{T}$, Ogomori $\mathrm{K}$, Tateishi J, et al. Formic acid pretreatment enhances immunostaining of cerebral and systemic amyloids. Lab Invest 1987;57:230-6.

13 Ikeda S, Allsop D, Glenner G. The morphology and distribution of plaques and related deposits in the brains of Alzheimer's disease and control cases: an immunohistochemical study using amyloid $\beta$-protein antibody. $L a b$ Invest 1989;60:113-22.

14 Yamaguchi $\mathrm{H}$, Hirai S, Morimatsu $\mathrm{M}$, et al. A variety of cerebral amyloid deposits in the brains of the Alzheimertype dementia demonstrated by $\beta$-protein immunostaintype dementia demonstrated by $\beta$-prote
ing. Acta Neuropathol 1988;533:1-9.

15 Guterman A, Smith RW. Neurological sequelae of boxing. Sports Medicine 1987;4:194-210.

16 Ikeda S, Allsop D, Glenner GG. Evidence of amyloid $\beta$ protein-immunoreactive early plaque lesions in Down's syndrome brains. Laboratory Investigations 1989;60 133-7.

17 Uhl GR, McKinney M, Hedreen J. Dementia pugilistica: loss of basal forebrain cholinergic neurons and cortical cholinergic markers. Ann Neurol 1982;12:99.

18 Rodgers-Johnson P, Garruto RM, Yanagihara R, et al. Amyotrophic lateral sclerosis and parkinsonism-dementia on Guam: A 30 year evaluation of clinical and neuropathologic trends. Neurology 1986;36:7-13.

19 Perry RH. Recent advances in neuropathology. Br Med Bull 1986;42:34-41.

20 Strich SJ. Shearing of nerve fibres as a cause of brain damage due to head injury. Lancet 1961;ii:443-8.

21 Flood DG, Buell SJ, Defiore DH, et al. Age-related dendritic growth in dentate gyrus of human brain is followed by regression in the "oldest old". Brain Research 1985;345:366-8.

22 Flood DG, Buell SJ, Horwitz GJ, et al. Dendritic extent in human dentate gyrus granule cells in normal aging and senile dementia. Brain Research 1987;402:205-16.

23 Ihara Y. Massive somatodendritic sprouting of cortical neurons in Alzheimer's disease. Brain Research 1988;459:138-44.

24 Adams CWM, Bruton CJ. The cerebral vasculature in dementia pugilistica. $J$ Neurol Neurosurg and Psychiatry 1989;52:600-4.

25 Rudelli R, Strom JO, Welch PT, et al. Post-traumatic premature Alzheimer's disease: neuropathologic findings and pathogenetic considerations. Arch Neurol 1982, 39:570-5

26 Amaducci LA, Fratiglioni L, Rocca WA, et al. Risk factors for Alzheimer's disease (AD): a case-control study on an Italian population. Neurology 1985;35(suppl 1), 277.

27 Chandra V, Bharucha NE, Schoenberg BS. Conditions associated with Alzheimer's disease at death: case-control study. Neurology 1986;36:209-11.

28 French LR, Schuman LM, Mortimer JA, et al. A casecontrol study of dementia of the Alzheimer's type. Am Epidemiol 1985;121:414-21.

29 Lewin W, Marshall TF de C, Roberts AJ. Long-term outcome after severe head injury. Br Med J 1979;2: 1533-8.

30 Walker E, Blumer D. The fate of World War II veterans with post-traumatic seizures. Arch Neurol 1989;46:23-6.

31 Saija A, Hayes RL, Lyeth BG, et al. The effect of concussive head injury on central cholinergic neurons. Brain Res head injury on cent 